\title{
Rethinking the urban physical environment for century-long lives: from age-friendly to longevity- ready cities
}

\author{
Chenghao Wang $\oplus^{1,2} \bowtie$, Diego Sierra Huertas ${ }^{2,3}$, John W. Rowe ${ }^{4}{ }^{4}$, Ruth Finkelstein ${ }^{5}$, \\ Laura L. Carstensen ${ }^{2,3}$ and Robert B. Jackson ${ }^{1,6}$
}

In response to increasing life expectancies and urbanization, initiatives for age-friendly cities seek to facilitate active and healthy aging by strengthening supports and services for older people. While laudable, these efforts typically neglect early-life exposures that influence long-term well-being. With a focus on the urban physical environment, we argue that longevity-ready cities can accomplish more than initiatives focused solely on old age. We review features of cities that cumulatively influence healthy aging and longevity, discuss the need for proactive interventions in a changing climate, and highlight inequities in the ambient physical environment, especially those encountered at early ages, that powerfully contribute to disparities in later life stages. Compared with strategies aimed largely at accommodating older populations, longevity-ready cities would aim to reduce the sources of disadvantages across the life course and simultaneously improve the well-being of older people.

S ubstantial efforts over the past century to reduce childhood mortality and adult morbidity raised global life expectancy at birth from $\sim 30$ years in 1900 to more than 72 years today, signifying remarkable improvement in human well-being ${ }^{1,2}$. Meanwhile, decreasing fertility has contributed to population aging in many countries throughout the world. The share of the older population (65 years or over) increased from $6 \%$ to $9 \%$ in the past 3 decades and is projected to climb to $16 \%$ in the next 3 decades $^{3}$. Increasing longevity amid rapid global urbanization poses outstanding challenges to societies in the development and planning of cities and communities, ranging from health service issues and social participation to ensuring that growing numbers of older citizens have safe and easy access to buildings, public infrastructures, and a range of ambient physical environments.

In general, societal responses to rising longevity aim to mitigate and adapt to the unexpected challenges brought by an increasing older population. Since the initial guidelines released by the World Health Organization (WHO) in 2007 (ref. ${ }^{4}$ ), numerous policies and initiatives have been proposed to create age-friendly cities and communities worldwide that would foster active and healthy aging ${ }^{5-7}$ (see definitions in Box 1). The WHO's framework for age-friendly cities focuses on eight interconnected domains (Fig. 1) that encompass the urban physical environment, social environment, and municipal services $^{4}$. This influential framework has raised wide awareness of and interest in population aging in urban planning and management $^{8,9}$, and at least half of the WHO Member States and thousands of cities and communities participate in related programs ${ }^{10,11}$.

Despite these encouraging achievements globally, the agefriendly cities framework has also been criticized for the inadequacy of the eight domains and the lack of measurability of 'age-friendliness $^{8,11}$. Moreover, while some age-friendly initiatives acknowledge in their missions and targets that age-friendly cities should go beyond being 'elderly friendly' by being friendly to people of all ages (Box 2), there is only modest evidence that they do so. This seemingly paradoxical trend is common in most age-friendly initiatives: actions and design principles in these initiatives, including WHO's guidelines, focus largely on older populations ${ }^{6,8}$. The WHO Global Database of Age-friendly Practices ${ }^{12}$, for example, documents 376 actions in more than 200 cities and communities globally (as of May 2021), yet more than $79 \%$ of them mainly target older adults. Despite language and sentiment that acknowledges needs across the life course, the main focus of age-friendly cities is on creating urban environments that are accessible and responsive to older people.

However, a growing body of evidence has shown that healthy and successful aging (Box 1) is strongly influenced by numerous factors throughout life. From a life-course perspective, attention has been focused on lifestyle factors, such as diet and physical activity $^{13,14}$; socioeconomic determinants, such as education, financial status, and social support ${ }^{15,16}$; and, increasingly, the characteristics of physical environments, such as green spaces and air quality ${ }^{17-19}$. In particular, continuous interactions with and cumulative exposures to the surrounding physical and social environments throughout life have vital roles in later-life outcomes. Therefore, designing and planning cities with responsive actions that largely or even exclusively focus on older persons, as is the case for most age-friendly actions, is insufficient.

For a population that is living four decades longer than the population a century ago, governments and societies have unique opportunities to intentionally plan from the moment children are born, instead of mitigating and adapting to the consequences by the time they reach old age. To better prepare people for sustainable, century-long lives in future cities, we need to shift from traditional age-friendly cities, which primarily focus on older people, to longevity-ready cities, a concept that extends the framework for

'Department of Earth System Science, Stanford University, Stanford, CA, USA. ${ }^{2}$ Stanford Center on Longevity, Stanford, CA, USA. ${ }^{3}$ Department of Psychology, Stanford University, Stanford, CA, USA. ${ }^{4}$ Mailman School of Public Health, Columbia University, New York, NY, USA. ${ }^{5}$ Brookdale Center for Healthy Aging, Hunter College, The City University of New York, New York, NY, USA. ${ }^{6}$ Woods Institute for the Environment and Precourt Institute for Energy, Stanford University, Stanford, CA, USA.凶e-mail: chenghao.wang@stanford.edu 


\section{Box 1 | A glossary of key terms used in this Perspective}

Active aging: A process that optimizes opportunities for health, participation, and security to enhance physical, social, and mental well-being throughout the life course $\mathrm{e}^{108}$.

Age-friendly cities: An inclusive and accessible urban environment designed to promote active and healthy aging in eight interconnected domains (outdoor spaces and buildings, transportation, housing, social participation, respect and social inclusion, civic participation and employment, communication and information, and community support and health services), which focuses on policies and actions aimed primarily to benefit older populations ${ }^{10,12}$.

Aging trajectory: The developmental course representing changes in functional capacities for individuals or groups.

Cumulative effects: Changes in human health, behaviors, and aging trajectory induced by combined effects of past, present, and potential future exposures to and interactions with surrounding physical and social environments.

Environmental factors: Characteristics and components of physical environments that affect aging trajectories.

Environmental stressors: Characteristics and components of physical environments, such as air pollutants and drinking-water contaminants, that hold detrimental consequences for aging trajectories.

Equitable aging: A process that provides people of all ages and abilities with equitable opportunities to thrive as they age ${ }^{70}$.

Functional capacity: The capability of an individual (such as respiratory capacity and cardiovascular performance) to perform daily tasks and activities ${ }^{100}$.

Health span: The length of time that an individual is healthy.

Healthy aging: A process that develops and maintains the healthrelated attributes that enable subjective and objective well-being at older age $\mathrm{e}^{109}$.

Healthy longevity: The positive outcomes produced by the alignment of health span and life span.

Life span: The length of time that an individual lives.

Longevity-ready cities: An inclusive, accessible, and equitable urban environment designed and planned to support older populations and simultaneously enable younger populations to age well, which, from a life-course perspective, considers cumulative effects of physical and social environments, changing climate, and disparities on active and healthy aging.

Successful aging: The status of low probability of disease and disease-related disability, high cognitive and physical functional capacity, and active engagement with life at older age ${ }^{13}$.

age-friendly cities to further consider the cumulative effects (Box 1) of the urban environment from a life-course perspective in urban planning and design. Although the urban social environment could be equally important, in this Perspective we mainly focus on the urban physical environment.

\section{Influence of the urban physical environment on healthy longevity begins long before older age}

The survival and health of older people living in urban settings are substantially influenced by various components of ambient physical environments, as has been underscored by numerous epidemiological studies ${ }^{20-23}$. Nevertheless, environmental influences on aging begin long before older age (Fig. 2). For example, many chronic diseases in later life, including cognitive decline and
Box 2 | Missions, targets, or definitions mentioned in initiatives and frameworks related to the concept of agefriendly cities

- In the WHO Global Network for Age-friendly Cities and Communities ${ }^{110}$ : "Creating age-friendly environments requires a process across the life course that progressively improves the fit between people's needs and the environments in which they live."

- In Global Age-friendly Cities: A Guide ${ }^{4}$ by the WHO: "Because active ageing is a lifelong process, an age-friendly city is not just 'elderly friendly."'

- In AARP Network of Age-Friendly States and Communities ${ }^{111}$ : "Well-designed, age-friendly communities foster economic growth and make for happier, healthier residents of all ages."

- In Making Your Community Livable for All Ages: What's Working! ${ }^{112}$ by the National Association of Area Agencies on Aging: "The National Association of Area Agencies on Aging defines a Livable Community as one that enables citizens to thrive across their lifespan."

dementia, can result from persistent exposure to airborne toxins in the outdoor urban environment emitted from traffic and industrial activities ${ }^{20,24}$. In fact, the rate of biological aging and chronic degenerative disease risk can be traced to environmental exposures in early childhood, even prenatal and neonatal stages, key stages of physical, cognitive, and emotional development. Several pregnancy outcomes can be influenced by ambient air pollution: maternal exposure to common urban airborne pollutants (such as $\mathrm{PM}_{2.5}$, $\mathrm{PM}_{10}, \mathrm{CO}$ and $\mathrm{NO}_{2}$ ) is associated with low birth weight and premature birth ${ }^{25,26}$, which often have long-term effects that include lower muscle strength ${ }^{27}$ and higher risks of chronic noncommunicable diseases (for example, cardiometabolic and glucose metabolism disorders) in adulthood and later life ${ }^{28}$. Furthermore, in utero and postnatal exposures to airborne toxins can alter lung structure and function, leading to increased risks of asthma and other chronic respiratory diseases in childhood and adulthood, and ultimately functioning in later life $\mathrm{e}^{29,30}$.

Adverse long-term impacts of air pollutants also arise indoors, where urban residents spend most of their time ${ }^{31}$. Indoor air quality is influenced by possible emissions from indoor combustion appliances and smoking and the air exchange with the outdoor environment. Especially, household air pollution emitted from solid fuel combustion (for example, coal, wood, and charcoal for cooking and heating) is among the leading risk factors for global attributable disability-adjusted life-years ${ }^{32}$, despite the substantially improved air quality in many countries. Other contaminants, such as formaldehyde, benzene, and lead, that are released from building materials and furnishings also have long-lasting, harmful effects on healthy aging and longevity ${ }^{33}$. As shown in epigenetic studies, exposure to airborne pollutants (both indoor and outdoor) during early-life stages may induce placental and newborn telomere shortening and accelerated biological aging ${ }^{26,34}$. The association between shorter telomere length and higher air-pollution exposure has been observed among children, young adults, and older adults ${ }^{35-37}$, and may further increase the risks of some age-related diseases ${ }^{38}$. In addition, exposure to secondhand smoke can delay neurodevelopment in children and adolescents and lead to poor academic achievement ${ }^{18,39}$. Moreover, higher air-pollution exposure for adults is associated with accelerated aging of the brain and arteries, faster cognitive decline, and higher risks of dementia, impairing later-life decision-making in ways that extend beyond physical health, such as decisions about financial matters ${ }^{18,24,40,41}$. 


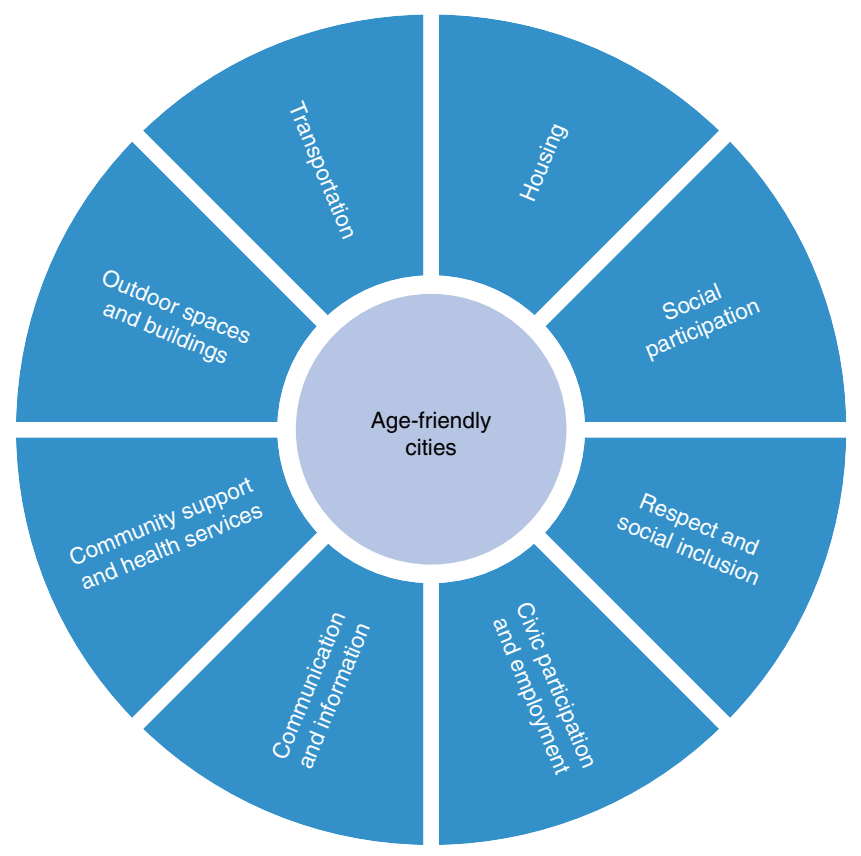

Fig. 1 | Eight interconnected domains of the WHO's age-friendly cities framework. These domains reflect different aspects of urban physical environments, social environments, culture, and health and social services. Adapted from ref. ${ }^{4}$

Likewise, chemical and microbial contaminants in municipal tap-water systems adversely influence people of all ages and exert short- and long-term toxic effects on healthy longevity ${ }^{42}$ (Box 1). Exposure to these contaminants is mainly attributable to poor sanitation and the lack of access to clean water in many cities in low-income and some middle-income countries, whereas in high-income countries it sometimes arises from aging urban water infrastructures. High-level prenatal and childhood exposure to arsenic through water is consistently associated with increased risks of cardiovascular diseases, pulmonary function impairment, respiratory diseases, and cancers in adulthood and later life ${ }^{43,44}$. Early-life exposures to lead in drinking water (from lead-bearing plumbing) can harm neuropsychological development, leading to many cognitive and neurobehavioral issues in subsequent life stages $^{45,46}$. Similarly, lifelong fluoride exposure may increase the risk of bone fractures in older adults, substantially affecting mobility and later-life quality ${ }^{47}$.

The thermal environment is another critical component of the urban physical environment that has long-lasting effects on healthy longevity. Both extremely hot and cold weather can be life-threatening to people of all ages, although young children, older people, and those with chronic medical conditions are more vulnerable ${ }^{22,48}$. Cities may further alter the impacts of background weather conditions on public health ${ }^{49}$. For instance, the urban heat island effect often increases outdoor temperature, intensifies heat stress, and eventually exposes inhabitants to higher risks of heat-related diseases and deaths $s^{50}$; by contrast, green spaces, water features, and shading infrastructure may effectively alleviate outdoor heat stress ${ }^{51}$. Indoor temperature is mainly controlled by available cooling and heating systems and building insulation. Buildings with limited access to cooling systems can exacerbate indoor heat stress in summers and trigger heatstroke and heart failure, whereas poorly insulated homes without effective heating systems in cold seasons can increase the risk of respiratory infection and cardiovascular diseases, all reducing the chance of survival to age 65 and older ${ }^{33,48,52}$. As shown in epidemiological surveys, survivors from heatstroke may experience permanent damage and lasting neurological sequelae (for example, functional impairment) with increased risks of mortality ${ }^{53,54}$.

Green spaces, such as parks and gardens, are commonly used in cities as recreational areas to enhance environmental quality and to promote public health. Many studies have observed strong associations between increased urban green spaces and reduced risks of various chronic diseases (for example, respiratory and cardiovascular diseases) across the lifetime ${ }^{55}$. This is partly because, compared to unshaded, impervious surfaces, well-designed urban green spaces can reduce outdoor temperatures on hot days and absorb and filter some air pollutants, directly contributing to improved thermal comfort and air quality ${ }^{56}$. Additionally, access to improved urban green spaces may promote physical activity and social interactions, benefiting both physical and mental health throughout life ${ }^{17,57,58}$. Urban green spaces also have an important role in influencing cognitive functions. Contact with green spaces in childhood can enhance working memory, attentiveness, and cognitive development ${ }^{59}$, and a higher level of access to green spaces during both childhood and adulthood may stave off later-life cognitive decline and contribute to more successful cognitive aging ${ }^{17}$.

As noted above, many components of the urban physical environment start impacting inhabitants in utero and continue throughout life, eventually affecting life quality at older age. In addition to pollutants and thermal stress, human exposure to many other urban environmental factors (for example, traffic conditions, noise, or access to parks) is closely related to the design and maintenance of buildings, planning of roads and transportation infrastructure, and physical structures of cities and neighborhoods, the influence of which can last a lifetime ${ }^{20,60,61}$. For instance, planning interventions that encourage walking, cycling, and the use of public transit in some cities can promote physical activity in all ages and effectively reduce the burden of disease and traffic-related injuries ${ }^{62}$. In particular, there is arguably no better prescription for healthy aging than exercise, and even walking is greatly influenced by neighborhood features such as sidewalks and streetlights ${ }^{63}$. Moreover, close and inevitable interactions between urban physical and social environments cumulatively shape human behavior and social activity/ engagement, and exert far-reaching impacts on cognitive functioning and neurological outcomes throughout life ${ }^{64}$.

\section{Designing the urban physical environment for longevity from a life-course perspective}

Distinct from most age-friendly city initiatives, longevity-ready cities acknowledge the cumulative effects of exposures to the ambient urban environment. Recently, attention has been devoted to the early-life social determinants of healthy and successful aging, such as social and professional networks ${ }^{65}$. Meanwhile, some existing urban-planning regulations, national/state standards, and initiatives (for example, the WHO's Healthy Cities initiative ${ }^{66}$ ) have benefited the health of the general population by improving the quality of the urban physical environment. Nevertheless, the cumulative impacts of the urban physical environment on active and healthy aging are still largely overlooked. From a life-course perspective, longevityoriented urban-design strategies and policies are imperative so that cities will be ready for an increasing population of individuals who are living longer. Here, we review several urban-planning examples that can potentially foster healthy longevity through improved physical environmental designs. These examples move beyond the common older-person-focused, age-friendly model, and are similar to or at least partly consistent with the longevity-ready concept.

The first example is the Community for All Ages initiative developed by the Mid-America Regional Council in the Kansas City metropolitan area. In response to increasing diverse populations in this region, the initiative aims to help city planners to identify measures to improve the life quality of residents beyond older people ${ }^{67}$. It outlines criteria and strategies that can be used in policy development 


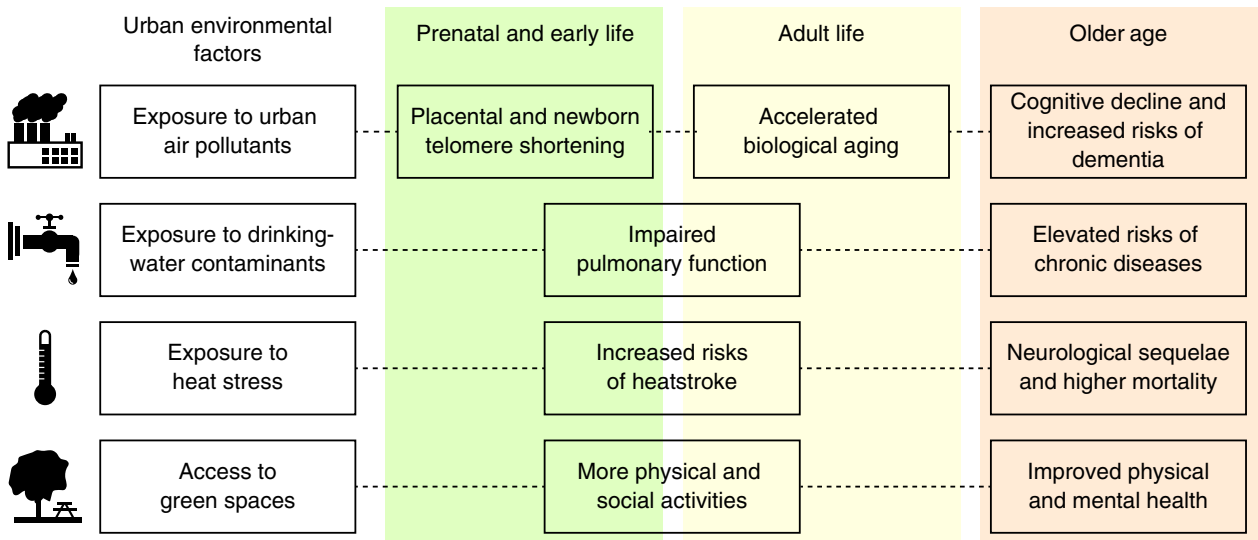

Fig. 2 | Examples of factors (see definitions in Box 1) in the urban physical environment and their potential long-term impacts on healthy longevity throughout life. The four examples of physical environmental components shown here are air pollutants, drinking contaminated water, heat stress, and access to green spaces. Health outcomes may be promoted or hindered across several life stages (for example, access to green spaces may promote physical and social activities for all life stages). Dashed lines represent statistical or causal relationships suggested by multiple lines of evidence (see main text).

and implementation for both physical and social environments. This initiative also focuses on bottom-up engagement of residents through discussion forums, workshops, and public-awareness campaigns, and has been financially supported by several regional and national organizations. Along with this initiative, a recognition program has been developed to encourage cities and communities to take steps from identifying present issues to adopting the Community for All Ages plans. Nearly 20 cities and communities in this region have either initiated or implemented related actions. Several cities and communities have adopted proactive strategies for the urban physical environment, including sustainable land-use development and regulations, promotion of housing adaptability, and designs of effective public transit and walkable neighborhoods to meet the needs of multiple generations.

Another example is a suite of policies and actions by the Atlanta Regional Commission (ARC) in the Atlanta metropolitan area. The ARC has developed a holistic, long-range regional plan with the goal of improving urban infrastructure, fostering healthy and livable communities, and building a robust and competitive economy $^{68}$. Several programs and initiatives, including the Lifelong Communities and Livable Centers Initiative, have provided financial resources and guidelines to communities to increase access to green spaces and other services, improve the safety of sidewalks and intersections, and eventually remove existing obstacles to aging in place. In particular, along with large-scale plans, such as transportation improvement and building renovations, multiple Lifelong Communities sites have implemented more visible and rapid projects, including farmers markets and community gardens, to sustain and enhance community engagement. Recognizing that longevity is determined by a combination of physical environmental factors, physical- and mental-health factors, and socioeconomic factors, the ARC recently launched a 5-year Live Beyond Expectations Regional Strategic Plan on aging ${ }^{69}$. This ambitious plan aims to use research to identify the key drivers of current life-expectancy disparities in this region, and to develop and execute strategies to close life-span gaps, while raising public awareness of life-expectancy determinants and inequities.

More recently, California released the Master Plan for Aging (MPA), a 10-year concerted blueprint for state agencies, multilevel governments, the private sector, and philanthropic organizations ${ }^{70}$. For a state in which the proportion of the population over age 60 is projected to increase to more than one-quarter by 2030 , this master plan seeks to ensure that all people can thrive throughout all life stages, and to promote healthy and equitable aging (Box 1).
As stated in the plan, the MPA is not simply for the current older population, but rather is a blueprint for aging across the entire life course, acknowledging the role of different life stages in reducing disparities in life expectancy. In particular, the MPA's first goal, Housing for All Ages and Stages, is closely related to the concept of longevity-ready cities. It includes strategies to increase affordable and safe housing options with improved community walkability, safe public transportation, convenient access to parks and other community spaces, and strong climate and disaster preparedness.

There are also plans and initiatives related to urban physical environmental designs in other countries that can potentially benefit residents from a life-course perspective, including the concept of Lifetime Neighbourhoods in the $\mathrm{UK}^{71}$, the All-Age-Friendly City project in the $\mathrm{UK}^{72}$, and the compact city planning in Toyama, Japan $^{73}$. In general, the design of longevity-ready cities should be multiscaled and should target various key aspects of the physical environment that cumulatively influence healthy longevity, for example by residential and commercial building retrofits, making modifications to building and community standards, replacing municipal water-distribution systems, developing walkable neighborhoods, redesigning public space and transportation systems, and introducing city-scale zoning regulations and land-use planning, among other steps. Although they have different objectives, similarities between longevity-ready urban designs and some city-wide sustainability plans signify the potential for integrating policies and optimizing financial investments and expenses.

\section{Longevity-ready cities in a changing climate}

The cumulative impact of the urban physical environment on active and healthy aging is not static. In fact, it will probably change with environmental factors that are influenced by climate change ${ }^{74,75}$. Cities in a warmer future are projected to experience increasing risks of individual and compound climate and weather extremes, such as more frequent heat waves, sea-level rise and coastal flooding, and intensified wildfire activities and associated air-pollution episodes ${ }^{76}$. These projected future changes, amid continuous global urbanization, can directly increase disaster-related mortality and morbidity, and indirectly exacerbate burdens of vector-borne disease outbreaks and mental illness, threatening the healthy longevity of not only older people, but urban inhabitants of all ages ${ }^{75}$. Future demographic changes in many countries could further amplify the negative impacts on longevity. For example, the exposure to unprecedented heat is projected to intensify in many countries owing to aging of their populations, despite the potential decrease in total 
population ${ }^{77}$. Nevertheless, existing age-friendly actions and practices often overlook these dynamic changes. From a life-course perspective, the design of urban physical environments for healthy, longer lives in the upcoming decades naturally calls for proactive actions to mitigate and adapt to climate change.

In response to increasing heat stress, urban heat-mitigation measures and adaptive social strategies need to be judiciously selected in different cities and informed by existing urban structure and composition, changing demographics, and local urban climate characteristics. Public infrastructure and housing units at increasing risks for future flooding (due to extreme rainfall events, hurricanes, or sea-level rise), especially those designed to support vulnerable populations and aging in place, require redesign and renovation months or years prior to potential disasters to improve their resistance ${ }^{78}$. Proactive and dynamic land-use planning and landscape design (for example, residential landscape and evacuation zones) close to or located at the wildland-urban interface ${ }^{79}$ should be implemented to reduce the impact of future risks related to mortality and morbidity posed by wildfire and smoke. Interventions tailored to local conditions and projected future changes of climate and populations, such as early warning systems ${ }^{80}$, will enhance the preparedness and resilience of longer-lived populations when they confront future extremes and disasters. Planning for climate and weather extremes years or even decades in advance will better position cities to embrace the upcoming waves of aging and promote healthy longevity. Note that, although we focus herein on urban physical environments, bidirectional influences between physical structures and social interactions also powerfully impact factors linked to healthy aging during extreme events ${ }^{81}$, ranging from the proximity of available helpers to the dire consequences of social isolation.

Of course, strategy implementation always demands weighing potential tradeoffs. Planning for longevity-ready cities requires a holistic consideration of how mitigation and adaptation strategies implemented in the urban physical environment might negatively affect the healthy longevity of urban residents. However, both agefriendly city initiatives and general urban planning have often failed to consider these unintended consequences. For example, despite its efficacy in cooling the environment and absorbing pollutants, urban vegetation also emits volatile organic compounds and pollen and can reduce the mixing of $\operatorname{air}^{56}$. As a result, greening cities without carefully examining vegetation species and arrangement may potentially lead to aggravated near-ground pollution levels and increased risk of asthma and allergy ${ }^{82}$. Ground-level reflective pavements, an urban heat-mitigation strategy used for roads and parking lots in many cities, may create unintended glare and increase pedestrian heat stress when reflecting solar radiation ${ }^{83}$. Policies to improve thermal comfort by providing free winter heating with solid fuels may result in aggregated air pollution and cumulatively contribute to life-expectancy reduction ${ }^{84}$. Overlooking these unforeseen detrimental outcomes when implementing longevity-oriented strategies to mitigate and adapt to climate change may exert extra burdens on public health and can jeopardize the healthy aging of urban residents.

\section{Longevity-ready cities reduce health disparities that emerge throughout life}

Interventions focusing only on older populations in most agefriendly city initiatives are unlikely to resolve existing gaps in healthy longevity across different groups of people. These gaps often stem from interactions between ambient physical environments and socioeconomic determinants that accumulate over the life course ${ }^{85,86}$. Environmental exposures are one of the major causes of the substantial differences in life expectancy across socioeconomic status ${ }^{24}$. Research across countries worldwide has shown that lower socioeconomic status is associated with limited access to healthy outdoor environments, higher exposure to environmental

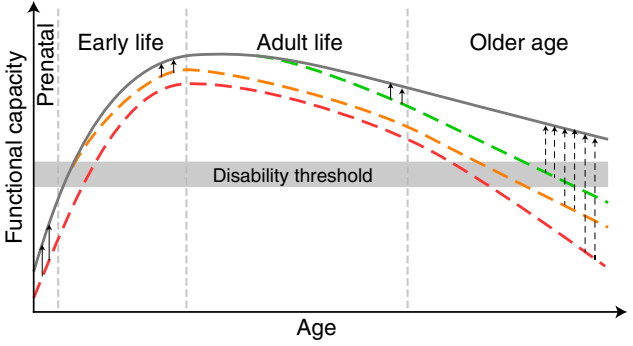

Fig. 3 | The influence of disparities in the urban physical environment on functional capacity that evolves across the life course. The gray band represents the disability threshold for functional capacity. The solid gray curve represents the high functional capacity group, whereas the dashed curves in different colors represent groups with relatively lower functional capacity due to exposures at earlier life stages. Gaps between the solid curve and dashed ones are gaps in functional capacity induced by possible disparities that emerge at different life stages. Solid and dashed arrows represent gaps that would be eliminated by longevity-oriented urban planning and current age-friendly city initiatives, respectively, while the length of each arrow denotes the amount of effort needed. Adapted from ref. ${ }^{100}$.

toxins and stressors (Box 1), and greater health risks at all ages ${ }^{87-89}$. For instance, children of color in Detroit, Michigan, face a disproportionate burden of lead exposure that begins in utero, which is associated with impaired brain development and cognitive functioning ${ }^{90}$. Disparities in traffic safety and access to green spaces are observed in many cities; wealthier and less racially and ethnically diverse neighborhoods tend to have fewer traffic injuries and more accessible green spaces ${ }^{91-94}$. Similar evidence exists for the indoor environment; for example, poverty is associated with a lack of access to clean fuels ${ }^{95}$, exposing poor urban inhabitants to increasing risks of chronic diseases. Likewise, groups with low socioeconomic status in urban populations are more likely to experience differential economic losses, infrastructure disruptions, and health risks (injuries, illnesses, and deaths) from natural disasters and climate change ${ }^{75,96,97}$. Differences in life expectancies and healthy longevity around the globe will probably persist, or even be magnified, if these gaps are overlooked. The COVID-19 pandemic has exemplified how existing, deeply-seated disparities can be further exacerbated, disproportionately harming low-income countries, communities of low socioeconomic status, and people from racial or ethnic minority groups ${ }^{98,99}$

Conceptually, gaps within populations at different ages can be expressed as discrepancies among individuals in their functional capacity (for example, respiratory capacity, brain functioning, muscle strength, and cardiovascular performance, all of which are closely related to life expectancy and healthy longevity; Box 1$)^{4,100}$ (Fig. 3). In general, the functional capacity gradually increases after the prenatal period, reaches its maximum in early adulthood stage, and then gradually decreases with age and experiences more rapid losses at older age, although the rate of change can vary (that is, it is not necessarily monotonic) with the interactions of individuals with the ambient environment. Meanwhile, gaps among population subgroups may also increase and become more remarkably visible in later life ${ }^{5}$, mainly because the disproportional exposure to environmental risks generally accumulates over time. Sustainable development of cities and communities requires the physical environment to be designed to minimize and prevent health disparities among individuals and improve the aging trajectory (Box 1) of all urban residents. Such efforts can be schematically described as the arrows in Fig. 3, which bump up the dashed curves to curb further deterioration. Compared with most age-friendly city initiatives that focus on older populations (dashed arrows) ${ }^{8}$, longevity-ready cities implement interventions that reduce disparities at all life stages 
(solid arrows). Theoretically, the latter approach will therefore probably be more efficient, and will require less effort (Fig. 3), to achieve a more equitable and integrated society and to better prepare for century-long lives.

\section{Discussion and outlook}

The concept of longevity-ready cities complements the age-friendly cities model by incorporating a life-course perspective, which emphasizes environmental influences that occur throughout life. Truly realizing longevity-ready cities demands a deeper understanding of environmental influences on aging and longevity. However, our current understanding of the ways in which urban physical environments cumulatively affect healthy longevity is mostly based on cross-sectional surveys or short-term longitudinal studies. More long-term prospective and retrospective cohort studies with controlled confounders are therefore imperative to disentangle the lifecourse impacts of urban physical environmental factors, especially those that have emerged in recent years (for example, smart home devices and autonomous vehicles). Similar studies that assess the long-term benefits and risks of existing policies and approaches are also important. Such cohort studies will substantially benefit implementation of future policies, given that the potential positive impacts of urban-planning policies on health may emerge slowly over the course of many years. One example is the widely implemented low-emission zones in many European cities (many have been in place since the late 2000s), which reduce air-pollution exposure. The long-term benefits of these zones were observed only recently ${ }^{101}$. Conclusions from these studies will also help quantify the tradeoffs between up-front costs of urban-planning interventions and the long-term benefits they bring to healthy longevity and prioritize the most cost-effective planning strategies when financial resources are limited.

With the focus of interventions on populations beyond older adults, many planning measures for longevity-ready cities are inherently similar to existing urban sustainable design strategies that improve general environmental quality (although with different objectives: healthy longevity versus general public health). This suggests that the proposed concept can be readily integrated into many ongoing efforts. Many initiatives for age-friendly cities that are aimed at improving the urban physical environment for older populations have encountered funding reductions and budget cuts $^{6,102}$. With the potential of being incorporated into a wider array of existing policies and investments, longevity-ready cities could better utilize available resources and alleviate some financial predicament. Furthermore, the needs of cohort studies on life-course environmental impacts, as a vital component of longevity-ready cities, can potentially motivate collaborations with research institutions and attract funding from agencies beyond local and regional governments. Therefore, mainstreaming a life-course perspective in existing ordinances and holistic plans should foster and accelerate the transitions of urban environments to prepare for and cope with population aging in future cities.

One of the challenges of achieving equitable aging is the disparity in health outcomes among different subgroups of older populations. This has been recognized as a core indicator in the assessments of age-friendly cities ${ }^{103}$. Similarly, resolving health disparities is an essential part of longevity-ready cities. With a life-course consideration of disparities in environmental exposures, longevity-ready cities could more effectively tackle later-life inequities by reducing environmental disadvantages in early life stages ${ }^{104,105}$. In addition, health and longevity disparities in urban populations are determined by several interacting, dynamic factors, which include not only physical environments, but the long-term impacts of social environments (for example, family engagement and civic involvement $)^{15}$ and the distribution of wealth and material resources ${ }^{106}$. Fundamentally resolving the health disparities in cities will require efforts toward addressing all these factors. Although we only focus on the urban physical environment herein, a life-course perspective of social domains in longevity-ready cities (Box 1 ) is equally impor$\operatorname{tant}{ }^{11}$, which can further improve the efficacy of social interventions and services.

The aging of urban populations can vary in different cities and countries and can dynamically change over time, as induced by regional and international migrations, economic developments, urban-regeneration projects and gentrification, and geographical, demographical, and cultural diversity ${ }^{5,8,107}$. This dynamic nature can become one of the major obstacles to the effectiveness and continuity of longevity-oriented policies and actions, which necessitates adaptive designs and frequent amendments. Knowledge transfers through communications and networks could help changing cities identify potential, evidence-based solutions. Similar to many age-friendly city initiatives ${ }^{4,8}$, the success of longevity-ready cities heavily relies on the concerted collaboration of multiple sectors, along with the engagement of policy makers, planners, designers, researchers, and beneficiaries of all ages. Integrating policies and research in longevity-oriented action plans will raise awareness of the determinants of healthy longevity among stakeholders (especially the private sector) while creating opportunities for partnerships. Moreover, the bottom-up participation of multiple generations in planning is critical, and this can stimulate their connections to one another and help reconcile potential conflicts by crafting actions that will fulfill different needs of different groups. Involving younger generations in the discussion to, for example, learn how they picture the cities they would like to live in when they grow old, could also benefit dynamic and adaptive policy making.

\section{Conclusions}

In an era of rapid global aging and urbanization, cities have unprecedented opportunities to mitigate and adapt to the unexpected challenges related to increased life expectancies and to positively support healthier, longer lives through intentional and well-informed planning. As century-long lives become the norm, it is imperative that we appreciate the cumulative effects of urban environments on healthy longevity, and design and reshape cities to optimize very long lives. Such a viewpoint calls for holistic considerations of how the urban physical environment may evolve in a changing climate and the pros and cons of various planning practices. In addition, life-course considerations of environmental exposures will minimize potential disparities in both life span and health span (Box 1), starting at the source. While the focus of this Perspective is on the urban physical environment, the concept of longevity-ready cities can be naturally extended to social determinants and municipal services and should permeate every phase of urban design and planning if possible.

\section{Data availability}

The source data of age-friendly practices and their target groups documented in the WHO Global Database of Age-friendly Practices are available from https://extranet.who.int/agefriendlyworld/afp/.

Received: 24 June 2021; Accepted: 22 October 2021; Published online: 10 December 2021

\section{References}

1. Wang, H. et al. Global, regional, and national life expectancy, all-cause mortality, and cause-specific mortality for 249 causes of death, 1980-2015: a systematic analysis for the Global Burden of Disease Study 2015. Lancet 388, 1459-1544 (2016)

2. Riley, J. C. Estimates of regional and global life expectancy, 1800-2001. Popul. Dev. Rev. 31, 537-543 (2005).

3. United Nations, Department of Economic and Social Affairs, Population Division. World Population Ageing 2019. Report No. ST/ESA/SER.A/444 (United Nations, 2020). 
4. World Health Organization. Global Age-friendly Cities: A Guide (World Health Organization, 2007)

5. Buffel, T., Handler, S. \& Phillipson C. Age-Friendly Cities and Communities: A Global Perspective (Policy Press, 2018).

6. Caro, F. G. \& Fitzgerald, K. G. International Perspectives on Age-Friendly Cities (Routledge, 2016).

7. Liddle, J., Scharf, T., Bartlam, B., Bernard, M. \& Sim, J. Exploring the age-friendliness of purpose-built retirement communities: evidence from England. Ageing Soc. 34, 1601-1629 (2014)

8. Moulaert, T. \& Garon, S. Age-Friendly Cities and Communities in International Comparison: Political Lessons, Scientific Avenues, and Democratic Issues (Springer, 2016).

9. Buffel, T., Phillipson, C. \& Scharf, T. Ageing in urban environments developing 'age-friendly' cities. Crit. Soc. Policy 32, 597-617 (2012).

10. World Health Organization. The Global Network for Age-friendly Cities and Communities: Looking Back Over the Last Decade, Looking Forward to the Next. Report No. WHO/FWC/ALC/18.4 (World Health Organization, 2018).

11. van Hoof, J., Marston, H. R., Kazak, J. K. \& Buffel, T. Ten questions concerning age-friendly cities and communities and the built environment. Build. Environ. 199, 107922 (2021).

12. World Health Organization. Global Database of Age-friendly Practices, https://extranet.who.int/agefriendlyworld/afp/ (accessed 30 May 2021)

13. Rowe, J. W. \& Kahn, R. L. Successful aging. Gerontologist 37, 433-440 (1997).

14. Gopinath, B., Kifley, A., Flood, V. M. \& Mitchell, P. Physical activity as a determinant of successful aging over ten years. Sci. Rep. 8, 10522 (2018)

15. Crosnoe, R. \& Elder, G. H. Successful adaptation in the later years: a life course approach to aging. Soc. Psychol. Q. 65, 309-328 (2002).

16. Britton, A., Shipley, M., Singh-Manoux, A. \& Marmot, M. G. Successful aging: the contribution of early-life and midlife risk factors. J. Am. Geriatr Soc. 56, 1098-1105 (2008).

17. Cherrie, M. P. C. et al. Green space and cognitive ageing: a retrospective life course analysis in the Lothian Birth Cohort 1936. Soc. Sci. Med. 196, 56-65 (2018)

18. Clifford, A., Lang, L., Chen, R., Anstey, K. J. \& Seaton, A. Exposure to air pollution and cognitive functioning across the life course-a systematic literature review. Environ. Res. 147, 383-398 (2016).

19. Lynch, J. \& Smith, G. D. A life course approach to chronic disease epidemiology. Annu. Rev. Public Health 26, 1-35 (2005).

20. Paul, K. C., Haan, M., Mayeda, E. R. \& Ritz, B. R. Ambient air pollution, noise, and late-life cognitive decline and dementia risk. Annu. Rev. Public Health 40, 203-220 (2019).

21. Åström, D. O., Bertil, F. \& Joacim, R. Heat wave impact on morbidity and mortality in the elderly population: a review of recent studies. Maturitas 69, 99-105 (2011)

22. Bunker, A. et al. Effects of air temperature on climate-sensitive mortality and morbidity outcomes in the elderly; a systematic review and metaanalysis of epidemiological evidence. EBioMedicine 6, 258-268 (2016)

23. Clarke, P. J. et al. Cognitive function in the community setting: the neighbourhood as a source of 'cognitive reserve'? J. Epidemiol. Community Health 66, 730-736 (2012)

24. Finch, C. E. \& Morgan, T. E. Developmental exposure to air pollution, cigarettes, and lead: Implications for brain aging. Annu. Rev. Dev. Psychol. 2 585-614 (2020).

25. Stieb, D. M., Chen, L., Eshoul, M. \& Judek, S. Ambient air pollution, birth weight and preterm birth: a systematic review and meta-analysis. Environ. Res. 117, 100-111 (2012).

26. Saenen, N. D. et al. Air pollution-induced placental alterations: an interplay of oxidative stress, epigenetics, and the aging phenotype? Clin. Epigenetics 11, 124 (2019)

27. Dodds, R. et al. Birth weight and muscle strength: a systematic review and meta-analysis. J. Nutr. Health Aging 16, 609-615 (2012).

28. de Mendonça, E. L. S. S., de Lima Macêna, M., Bueno, N. B., de Oliveira, A C. M. \& Mello, C. S. Premature birth, low birth weight, small for gestational age and chronic non-communicable diseases in adult life: a systematic review with meta-analysis. Early Hum. Dev. 149, 105154 (2020).

29. Miller, M. D. \& Marty, M. A. Impact of environmental chemicals on lung development. Environ. Health Perspect. 118, 1155-1164 (2010).

30. Guarnieri, M. \& Balmes, J. R. Outdoor air pollution and asthma. Lancet 383, 1581-1592 (2014)

31. Klepeis, N. E. et al. The National Human Activity Pattern Survey (NHAPS) a resource for assessing exposure to environmental pollutants. J. Expo. Sci. Environ. Epidemiol. 11, 231-252 (2001).

32. Murray, C. J. L. et al. Global burden of 87 risk factors in 204 countries and territories, 1990-2019: a systematic analysis for the Global Burden of Disease Study 2019. Lancet 396, 1223-1249 (2020).

33. World Health Organization. WHO Housing and Health Guidelines (World Health Organization, 2018)
34. Song, L. et al. Effects of maternal exposure to ambient air pollution on newborn telomere length. Environ. Int. 128, 254-260 (2019).

35. Lin, N. et al. Accumulative effects of indoor air pollution exposure on leukocyte telomere length among non-smokers. Environ. Pollut. 227, 1-7 (2017).

36. Moslem, A. et al. Association of exposure to air pollution and telomere length in preschool children. Sci. Total Environ. 722, 137933 (2020)

37. Martens, D. S. \& Nawrot, T. S. Ageing at the level of telomeres in association to residential landscape and air pollution at home and work: a review of the current evidence. Toxicol. Lett. 298, 42-52 (2018).

38. Blasco, M. A. Telomeres and human disease: ageing, cancer and beyond. Nat. Rev. Genet. 6, 611-622 (2005).

39. Chen, R., Clifford, A., Lang, L. \& Anstey, K. J. Is exposure to secondhand smoke associated with cognitive parameters of children and adolescents?-a systematic literature review. Ann. Epidemiol. 23, 652-661 (2013).

40. Zhang, X., Chen, X. \& Zhang, X. The impact of exposure to air pollution on cognitive performance. Proc. Natl Acad. Sci. USA 115, 9193-9197 (2018).

41. Gamble, K. J., Boyle, P. A., Yu, L. \& Bennett, D. A. Aging and financial decision making. Manag. Sci. 61, 2603-2610 (2015).

42. Schwarzenbach, R. P., Egli, T., Hofstetter, T. B., von Gunten, U. \& Wehrli, B. Global water pollution and human health. Annu. Rev. Environ. Resour. 35 109-136 (2010).

43. Farzan, S. F., Karagas, M. R. \& Chen, Y. In utero and early life arsenic exposure in relation to long-term health and disease. Toxicol. Appl. Pharmacol. 272, 384-390 (2013).

44. Evans, S., Campbell, C. \& Naidenko, O. V. Cumulative risk analysis of carcinogenic contaminants in United States drinking water. Heliyon 5, e02314 (2019).

45. Patrick, L. Lead toxicity, a review of the literature. Part I: exposure, evaluation, and treatment. Altern. Med. Rev. 11, 2-22 (2006).

46. Patel, A. I., Hecht, C. E., Cradock, A., Edwards, M. A. \& Ritchie, L. D. Drinking water in the United States: implications of water safety, access, and consumption. Annu. Rev. Nutr. 40, 345-373 (2020).

47. Li, Y. et al. Effect of long-term exposure to fluoride in drinking water on risks of bone fractures. J. Bone Miner. Res. 16, 932-939 (2001).

48. Anderson, B. G. \& Bell, M. L. Weather-related mortality: how heat, cold, and heat waves affect mortality in the United States. Epidemiology 20 205-213 (2009).

49. Oke, T. R., Mills, G., Christen, A. \& Voogt, J. A. Urban Climates (Cambridge University Press, 2017).

50. Tan, J. et al. The urban heat island and its impact on heat waves and human health in Shanghai. Int. J. Biometeorol. 54, 75-84 (2010).

51. Harlan, S. L. \& Ruddell, D. M. Climate change and health in cities: impacts of heat and air pollution and potential co-benefits from mitigation and adaptation. Curr. Opin. Environ. Sustain. 3, 126-134 (2011).

52. Hajat, S., Kovats, R. S. \& Lachowycz, K. Heat-related and cold-related deaths in England and Wales: who is at risk? Occup. Environ. Med. 64, 93-100 (2007).

53. Argaud, L. Short- and long-term outcomes of heatstroke following the 2003 heat wave in Lyon, France. Arch. Intern. Med. 167, 2177 (2007).

54. Epstein, Y. \& Yanovich, R. Heatstroke. N. Engl. J. Med. 380, 2449-2459 (2019).

55. Douglas, O., Lennon, M. \& Scott, M. Green space benefits for health and well-being: a life-course approach for urban planning, design and management. Cities 66, 53-62 (2017)

56. Demuzere, M. et al. Mitigating and adapting to climate change: multifunctional and multi-scale assessment of green urban infrastructure. Environ. Manag. 146, 107-115 (2014).

57. Hunter, R. F. et al. The impact of interventions to promote physical activity in urban green space: a systematic review and recommendations for future research. Soc. Sci. Med. 124, 246-256 (2015).

58. Middleton, L. E., Barnes, D. E., Lui, L.-Y. \& Yaffe, K. Physical activity over the life course and its association with cognitive performance and impairment in old age. J. Am. Geriatr. Soc. 58, 1322-1326 (2010).

59. Dadvand, P. et al. Green spaces and cognitive development in primary schoolchildren. Proc. Natl Acad. Sci. USA 112, 7937-7942 (2015).

60. Ige-Elegbede, J. et al. Designing healthier neighbourhoods: a systematic review of the impact of the neighbourhood design on health and wellbeing. Cities Health https://doi.org/10.1080/23748834.2020.1799173 (2020)

61. Cedeño-Laurent, J. G. et al. Building evidence for health: green buildings, current science, and future challenges. Annu. Rev. Public Health 39, 291-308 (2018).

62. Stevenson, M. et al. Land use, transport, and population health: estimating the health benefits of compact cities. Lancet 388, 2925-2935 (2016).

63. Notthoff, N. \& Carstensen, L. L. Promoting walking in older adults: perceived neighborhood walkability influences the effectiveness of motivational messages. J. Health Psychol. 22, 834-843 (2017).

64. Berman, M. G., Kardan, O., Kotabe, H. P., Nusbaum, H. C. \& London, S. E. The promise of environmental neuroscience. Nat. Hum. Behav. 3, 414-417 (2019). 
65. The Economist Intelligence Unit. Ready for 100? Preparing for Longevity in Singapore (The Economist Intelligence Unit, 2018).

66. Edwards, P. \& Tsouros, A. D. A Healthy City is an Active City: A Physical Activity Planning Guide (WHO Regional Office for Europe, 2008).

67. Mid-America Regional Council. Making Your Community Work for All Ages-A Toolkit for Cities (Mid-America Regional Council, 2013).

68. Atlanta Regional Commission. The Region's Plan Policy Framework (Atlanta Regional Commission, 2015)

69. Atlanta Regional Commission. Live Beyond Expectations Regional Strategic Plan Framework 2020-2025 (Atlanta Regional Commission, 2020).

70. Newsom, G. Master Plan for Aging (California Department of Aging, 2021)

71. Bevan, M. \& Croucher, K. Lifetime Neighbourhoods (Department for Communities and Local Government, 2011).

72. Facer, K., Horner, L. \& Manchester, H. Towards All-Age-Friendly Cities: Working Paper 1 of the Bristol All-Age-Friendly City Group (Univ. of Bristol, 2014).

73. Kriss, P., Miki-Imoto, H., Nishimaki, H. \& Riku, T. Toyama City: Compact City Development (The World Bank, 2021).

74. Watts, N. et al. The 2020 report of The Lancet Countdown on health and climate change: responding to converging crises. Lancet 397, 129-170 (2021).

75. Watts, N. et al. Health and climate change: policy responses to protect public health. Lancet 386, 1861-1914 (2015).

76. IPCC. Global Warming of $1.5^{\circ} \mathrm{C}$ (eds Masson-Delmotte, V. et al.) (2018)

77. Park, C.-E., Jeong, S., Harrington, L. J., Lee, M.-I. \& Zheng, C. Population ageing determines changes in heat vulnerability to future warming. Environ. Res. Lett. 15, 114043 (2020).

78. Aerts, J. C. J. H. \& Botzen, W. J. W. Flood-resilient waterfront development in New York City: bridging flood insurance, building codes, and flood zoning. Ann. N. Y. Acad. Sci. 1227, 1-82 (2011).

79. Syphard, A. D., Massada, A. B., Butsic, V. \& Keeley, J. E. Land use planning and wildfire: development policies influence future probability of housing loss. PLOS ONE 8, e71708 (2013)

80. Lowe, D., Ebi, K. L. \& Forsberg, B. Heatwave early warning systems and adaptation advice to reduce human health consequences of heatwaves. Int. J. Environ. Res. Public. Health 8, 4623-4648 (2011).

81. Klinenberg, E. Heat Wave: A Social Autopsy of Disaster in Chicago (Univ. of Chicago Press, 2015)

82. Salmond, J. A. et al. Health and climate related ecosystem services provided by street trees in the urban environment. Environ. Health 15, S36 (2016).

83. Wang, C., Wang, Z.-H., Kaloush, K. E. \& Shacat, J. Cool pavements for urban heat island mitigation: a synthetic review. Renew. Sustain. Energy Rev. 146, 111171 (2021).

84. Chen, Y., Ebenstein, A., Greenstone, M. \& Li, H. Evidence on the impact of sustained exposure to air pollution on life expectancy from China's Huai River policy. Proc. Natl Acad. Sci. USA 110, 12936-12941 (2013).

85. Kuh, D., Karunananthan, S., Bergman, H. \& Cooper, R. A life-course approach to healthy ageing: maintaining physical capability. Proc. Nutr. Soc. 73, 237-248 (2014)

86. Luo, Y. \& Waite, L. J. The impact of childhood and adult SES on physical, mental, and cognitive well-being in later life. J. Gerontol. Ser. B 60 , S93-S101 (2005).

87. Evans, G. W. \& Kantrowitz, E. Socioeconomic status and health: the potential role of environmental risk exposure. Annu. Rev. Public Health 23, 303-331 (2002).

88. Hsu, A., Sheriff, G., Chakraborty, T. \& Manya, D. Disproportionate exposure to urban heat island intensity across major US cities. Nat. Commun. 12, 2721 (2021).

89. Hajat, A., Hsia, C. \& O’Neill, M. S. Socioeconomic disparities and air pollution exposure: a global review. Curr. Environ. Health Rep. 2, 440-450 (2015).

90. Cassidy-Bushrow, A. E. et al. Burden of higher lead exposure in AfricanAmericans starts in utero and persists into childhood. Environ. Int. 108, 221-227 (2017).

91. Nesbitt, L., Meitner, M. J., Girling, C., Sheppard, S. R. J. \& Lu, Y. Who has access to urban vegetation? A spatial analysis of distributional green equity in 10 US cities. Landsc. Urban Plan. 181, 51-79 (2019).

92. Rigolon, A., Browning, M. H. E. M., Lee, K. \& Shin, S. Access to urban green space in cities of the Global South: a systematic literature review. Urban Sci. 2, 67 (2018).

93. Noland, R. B., Klein, N. J. \& Tulach, N. K. Do lower income areas have more pedestrian casualties? Accid. Anal. Prev. 59, 337-345 (2013).

94. Yu, C.-Y. Environmental supports for walking/biking and traffic safety: income and ethnicity disparities. Prev. Med. 67, 12-16 (2014).
95. Zhou, Z. et al. Household and community poverty, biomass use, and air pollution in Accra, Ghana. Proc. Natl Acad. Sci. USA 108 11028-11033 (2011).

96. Gasper, R., Blohm, A. \& Ruth, M. Social and economic impacts of climate change on the urban environment. Curr. Opin. Environ. Sustain. 3, 150-157 (2011).

97. Masozera, M., Bailey, M. \& Kerchner, C. Distribution of impacts of natural disasters across income groups: a case study of New Orleans. Ecol. Econ. 63, 299-306 (2007).

98. Jowell, A., Carstensen, L. L. \& Barry, M. A life-course model for healthier ageing: lessons learned during the COVID-19 pandemic. Lancet Healthy Longev. 1, e9-e10 (2020).

99. Abedi, V. et al. Racial, economic, and health inequality and COVID-19 infection in the United States. J. Racial Ethn. Health Disparities 8, 732-742 (2021).

100. Kalache, A. \& Kickbusch, I. A global strategy for healthy ageing. World Health 50, 4-5 (1997).

101. Klauber, H. et al. Killing Prescriptions Softly: Low Emission Zones and Child Health from Birth to School (IZA Institute of Labor Economics, 2021).

102. Buffel, T. \& Phillipson, C. Can global cities be 'age-friendly cities'? Urban development and ageing populations. Cities 55, 94-100 (2016).

103. World Health Organization. Measuring the Age-Friendliness of Cities: A Guide to Using Core Indicators (World Health Organization, 2015).

104. Miller, J. et al. Effectively Reducing Race Differences In Old Age Demands a Life Course Approach (AARP International, 2021).

105. Jones, N. L. et al. Life course approaches to the causes of health disparities. Am. J. Public Health 109, S48-S55 (2019).

106. Wu, Y.-T. et al. Education and wealth inequalities in healthy ageing in eight harmonised cohorts in the ATHLOS consortium: a population-based study. Lancet Public Health 5, e386-e394 (2020).

107. Marois, G., Bélanger, A. \& Lutz, W. Population aging, migration, and productivity in Europe. Proc. Natl Acad. Sci. USA 117, 7690-7695 (2020).

108. World Health Organization. Active Ageing: A Policy Framework. Report No. WHO/NMH/NPH/02.8 (World Health Organization, 2002).

109. World Health Organization. World Report on Ageing and Health (World Health Organization, 2015).

110. WHO Global Network for Age-friendly Cities and Communities. Membership in the Global Network of Age-friendly Cities and Communities (GNAFCC) (World Health Organization, 2019).

111. AARP. AARP Network of Age-Friendly States and Communities, https://www. aarp.org/livable-communities/network-age-friendly-communities/ (accessed 03 Jun 2021).

112. National Association of Area Agencies on Aging (n4a). Making Your Community Livable for All Ages: What's Working! (National Association of Area Agencies on Aging, 2015).

\section{Acknowledgements}

This study was supported by the Stanford Center on Longevity's New Map of Life initiative. We thank J. Randell-Khan for her assistance with the revision and K. Smith for his contributions throughout the project.

\section{Author contributions}

C. W., D. S. H., L. L. C., and R. B. J. contributed to the conceptualization and design of this study. C. W. and D. S. H. conducted the formal analysis and drafted the manuscript. J. W. R., R. F., L. L. C., and R. B. J. critically reviewed the manuscript. All authors revised the manuscript and approved the final version. L. L. C. and R. B. J. secured funding for the program.

\section{Competing interests}

The authors declare no competing interests.

\section{Additional information}

\section{Correspondence should be addressed to Chenghao Wang.}

Peer review information Nature Aging thanks Thomas Scharf and the other, anonymous, reviewer(s) for their contribution to the peer review of this work.

Reprints and permissions information is available at www.nature.com/reprints.

Publisher's note Springer Nature remains neutral with regard to jurisdictional claims in published maps and institutional affiliations.

(c) Springer Nature America, Inc. 2021 